\title{
INTERDISCIPLINARIDADE NA ESCOLA: VIVÊNCIAS REFLETIDAS ${ }^{*}$
}

\author{
Maria de Fátima TeiXeira Barreto ${ }^{* *}$
}

\begin{abstract}
Resumo
A questão da interdisciplinaridade tem sido motivo de constantes reflexôes entre educadores. No Centro de Ensino e Pesquisa Aplicada à Educação (Cepae/UFG) tivemos momentos em que discutimos e vivenciamos situaçóes que apontaram caminhos para uma ação interdisciplinar. Torna-se, então, oportuno, neste ensaio, refletir teoricamente sobre essas experiências, relacionando interdisciplinaridade, conhecimento e organização do trabalho pedagógico, vez que a clareza de tais concepçóes pode favorecer uma ação pedagógica transformadora. Para encaminhar a reflexáo proposta, busco a compreensão do termo interdisciplinaridade, apresento e reflito acerca de nossas tentativas de desenvolvimento de trabalhos interdisciplinares no movimento das mudanças ocorridas na organização do trabalho pedagógico.
\end{abstract}

PalaVRas-ChaVE: interdisciplinaridade, ação interdisciplinar.

\section{Interdisciplinarity in school: memories reflected}

\section{Abstract}

Some issues about interdisciplinarity has been the reasons for constant reflections among educators. In Cepae (Centro de Ensino e Pesquisa Aplicada à Educação) we had moments when we discussed and experienced situations that indicated paths to interdisciplinarity work. It was a time for reflecting upon those experiences relating interdisciplinary, knowledge and pedagogical work organization since a clear meaning of such conceptions can favor a transforming pedagogical action. In this text, I seek for an understanding of the term interdisciplinarity and I also present and reflect upon our trials of developing interdisciplinary work in the movement of changings occurred in the pedagogical work organization.

KEY WORDS: interdisciplinarity, interdisciplinary action.

\section{POR UMA CONCEPÇÃO DE INTERDISCIPLINARIDADE EM AMBIENTE ESCOLAR}

Estudos interdisciplinares e interdisciplinaridade têm se constituído como linha de pesquisa na área educacional. Guimarães e Pinto (2005)

\footnotetext{
* Este texto apresenta as reflexões e preocupaçóes da autora a partir de vivências das quais participou como professora e pesquisadora atuando no Ensino Fundamental no Cepae/UFG.

** Professora de Fundamentos e Metodologia de Matemática nas séries iniciais e Educação Infantil da Faculdade de Educação da Universidade Federal de Goiás; doutora em Educação Matemática Unesp de Rio Claro. E-mail: fato823@terra.com.br.
} 


\section{Revista Solta a Voz, v. 19, n. 2}

fazem um levantamento dos estudos realizados envolvendo interdisciplinaridade e a apresenta como uma tendência mundial, que surge em função das exigências que o mundo, em sua complexidade, tem feito aos especialistas para que transcendam seus limites.

Machado (1995) justifica o surgimento desta discussão em ambiente escolar pela busca de uma unidade perdida, da interaçâo e da complementaridade nas açóes envolvendo diferentes disciplinas. Para o autor (idem, p. 180) esta discussão tornou-se necessária por conta de dois aspectos que se relacionam:

[...] em primeiro lugar, uma fragmentaçáo crescente dos objetos do conhecimento nas diversas áreas, sem a contrapartida do incremento de uma visão de conjunto do saber instituído [...] em segundo lugar, por parecer [...] cada vez mais difícil o enquadramento de fenômenos que ocorrem fora da escola no âmbito de uma única disciplina.

Conforme Cachapuz et al. (2005), estudos atuais indicam a necessidade dos saberes relativos às disciplinas serem aprendidos através de estudos de situaçóes problemas que façam sentido para os alunos e não através do estudo de conceitos e princípios isolados. Esta formatação possibilitaria, mais que uma formaçáo propedêutica, uma educação para a cidadania.

Para Macedo e Campos (2000), o conhecimento tratado na escola apresenta-se de modo tão simplificado que se distancia do saber necessário a uma atuação efetiva fora da escola. Assim, mesmo obtendo sucesso nas atividades escolares, muitas pessoas se tornam impotentes diante do mundo complexo no qual vivem.

Pietrocola et al. (2005) corroboram com a compreensão de Macedo e Campos (2000) ao considerarem que, em sala de aula, simplificamos os problemas e situaçóes para integrá-los às teorias. Para os autores deveríamos seguir o caminho inverso, ou seja, submeter os conhecimentos disponíveis a projetos de ação sobre o mundo, tal como o fazem os profissionais que lidam com a ciência aplicada, como fazem médicos, dentistas e estudiosos que trabalham na tentativa de solucionar problemas reais. Estes autores desenvolveram vários projetos em sala de aula, fundamentados em Fourez (1995), que indica para o ambiente de sala de aula o estudo dos conhecimentos por projetos, que apresentam como características a instabilidade, a inexatidão e uma forte influência do contexto no qual estáo inseridos. 
Para Fourez (1995), conforme nos coloca Pinho-Alves e Schmitz (2004), uma educação científica através de projetos rompe com o paradigma das disciplinas ao apresentar um tema compartilhado; fazer uso do senso comum e do conhecimento de várias disciplinas científicas com vistas à realização de um produto final, que também é compartilhado; apresentar um projeto explícito e compartilhado; permitir a negociação compromissada com o projeto e com o produto final. Vê-se que compartilhar torna-se palavra chave numa proposta interdisciplinar, e para tal a comunicação é fundamental.

Fazenda (1994) apresenta a comunicação como o pressuposto básico para o desenvolvimento da interdisciplinaridade. Acrescenta ainda que não há comunicação sem participação, sem que haja nas escolas uma estrutura que possibilite a troca, o compartilhar de vivências e compreensóes. Para a autora (idem, p. 92), "O projeto interdisciplinar parte da dúvida, da pergunta, das indagaçóes, do diálogo da troca, da reciprocidade”.

Desta forma, para que possamos ter vivências interdisciplinares na escola, faz-se necessário um grupo de professores unidos pelo desejo de realizar tal prática e da autonomia para pensar o seu fazer pedagógico: "a metodologia interdisciplinar parte de uma liberdade científica, alicerça-se no diálogo e na colaboração, funda-se no desejo de inovar, de criar, de ir além e exercita-se na arte de pesquisar" (Fazenda, 1994, p. 69).

\section{VIVÊNCIAS INTERDISCIPLINARES (OU NÃO): CAMINHOS PERCORRIDOS}

No Cepae/UFG há muito se busca uma ação interdisciplinar, tanto no campo do ensino quanto na pesquisa, para contrapor-se à organizaçáo independente das disciplinas. Os registros feitos pelos professores que atuam na primeira fase do Ensino Fundamental, em seus projetos de ensino e no projeto político pedagógico da escola, mostram que, de fato, essa não é uma preocupação recente.

Este ensaio faz uma reflexão sobre interdisciplinaridade na escola num diálogo entre estudos teóricos sobre o tema e os caminhos já percorridos no Cepae desde 1990, motivado pelo desejo de realizar um trabalho interdisciplinar de modo que o educando pudesse conhecer um pouco sobre a cultura institucionalizada e também se conhecer, conhecer sua realidade. 
As ações descritas foram desenvolvidas entre os anos de 1990 e os dias atuais e podem ser organizadas em grupos conforme o modo de encaminhamento didático-metodológico, sendo o centro do processo a literatura, os conteúdos de uma determinada área e os temas geradores. Estaremos apresentando tais tentativas de realização de açóes interdisciplinares contextualizadas nos modo de organização do trabalho pedagógico da escola, analisando-as em suas características a partir dos estudos de Fourez (1995) e Pinho-Alves e Schmitz (2004), e, finalmente, relacionando os caminhos percorridos para o trabalho interdisciplinar nas séries iniciais no Cepae mediante tais mudanças.

\section{A literatura em foco}

No início da década de 90 nós, professores das séries inicias do ensino fundamental do Cepae, assumíamos o trabalho com mais de uma disciplina em uma mesma série (somente não trabalhamos com artes e educação física), tomando a literatura infantil para a tematização de valores humanos como possibilidade de trabalho para a sala de aula. Orientados por programas de incentivo à leitura e estudos na área, nos apoiávamos em obras literárias, tanto na formação de leitores quanto na formação de pessoas, por considerar que por intermédio das obras seria possível discutir sentimentos e situaçóes comuns à própria vida. Assim, por algum tempo, os temas foram abordados a partir da literatura infantil, em especial obras literárias que imitam, negam e/ou brincam com as condiçóes de existência dos alunos.

O trabalho se dava a partir de um planejamento coletivo entre os professores de uma mesma série e turmas diferentes, que selecionavam obras literárias que pareciam significativas para o grupo de alunos com os quais estavam trabalhando e, a partir das obras selecionadas, buscavam a aproximação das várias áreas de conhecimento como instrumentos para re-leitura dos temas abordados. Como exemplo, os professores elegeram a temática "medo", inspirados pelas obras literárias: Quem tem medo do escuro (Joly, Fanny); Alguns medos e seus segredos (Machado, Ana Maria); Quem salta mais longe (Coelho, Ronaldo Simôes); Chapeuzinho Vermelho (conto popular); Chapeuzinho Amarelo (Buarque, Chico). A partir da leitura, da dramatização e da reescrita de partes da estória produzindo mudanças no texto, foram abordados os diversos tipos de medo que assolavam os alunos e seus familiares. 
Foram pesquisados os principais medos vividos pelos grupos com os quais os alunos conviviam e os dados serviram para o estudo dos números, operaçōes, gráficos e tabelas. A partir do levantamento feito foi realizada uma discussão para pensar modos de enfrentamento desses medos. Neste contexto, os alunos produziram textos nos diários, bilhetes, cartas, receitas; foi discutido como o medo impulsiona certas atitudes do homem frente ao mundo em que vive (solidariedade, amizade etc.) e a criação de objetos que modificam o modo de viver coletivamente do homem (muros, portóes, poupança, armas, cofres etc.).

Ainda nesta teia de significaçóes, passamos a refletir acerca do cuidado dos nossos governantes para com nossa segurança, para com nossa educação, para com a nossa saúde, questôes sempre presentes nos levantamentos feitos.

Tomando como referência os estudos de Fourez (1995) e PinhoAlves e Schmitz (2004), constatamos que esta vivência apresenta características de um trabalho interdisciplinar por possibilitar ir além dos limites das disciplinas, partir para um tema compartilhado, fazer uso de senso comum e de disciplinas científicas. Entretanto, não apresenta um projeto compartilhado e um produto final explícito, de modo que náo se torna possível a negociação da ação das disciplinas de modo compromissado com um produto. Trata-se de uma proposta de trabalho interdisciplinar de aproximação global.

\section{O conteúdo de uma disciplina em foco}

Outra tentativa de se trabalhar de modo interdisciplinar se deu entre os anos de 1994 a 1996, ainda tendo professores atuando com mais de uma disciplina em uma mesma série. Desta vez, mais preocupados com o plano de curso a ser cumprido, foi desenvolvida em algumas turmas, nas quais os professores interessados por estas discussóes organizaram seu planejamento de modo que, a cada período, uma disciplina conduzia o tema a ser explorado. O professor, ao priorizar uma determinada área de conhecimento na definição do tema, buscava o cumprimento do plano de curso em consonância com um tratamento que se fizesse interdisciplinar, em que várias disciplinas tratavam o mesmo tema, em sala de aula, sob um foco particular à sua área de conhecimento. Nessa proposta, uma das disciplinas se tornava, naquele período, central, enquanto as outras, quan- 
do podiam contribuir o faziam, mesmo que não atendesse ao seu plano de curso; quando o professor não considerava possível tal envolvimento, devido a limitaçóes próprias ou do tema, visto que se tratava de um tema/ conteúdo e não um tema gerador de discussão em primeira instância, havia um "afastamento" momentâneo do mesmo e o trabalho coletivo voltava a ser retomado em outro momento de planejamento. Os valores humanos e a literatura, quando possíveis, também permeavam as atividades.

Tal vivência pode ser conhecida em detalhes no trabalho de Teixeira (1994), quando trazemos um relato do trabalho desenvolvido ao estudar o sistema respiratório. Nessa temática, a disciplina central era Ciências Biológicas, mas outras áreas de conhecimentos buscaram possíveis articulaçóes. Nas aulas de Língua Portuguesa foi explorada a história Apanhei assim mesmo, de Ruth Rocha, e, ainda, placas colocadas em locais públicos proibindo o ato de fumar. Os alunos produziram bilhetes para fumantes e folder conscientizando as pessoas dos malefícios do cigarro; em Matemática foi relacionado o gasto com a compra de cigarros aos valores necessários para comprar leite e pão (entre outros gêneros alimentícios de consumo diário), buscando mais um motivo para que o vício fosse abandonado pelos fumantes ou para que um não-fumante não se inicie nesse vício; houve um afastamento do tema nas aulas de História e Geografia. Entendemos que tal articulação poderia ter sido feita se nós, professores, tivéssemos nos atentado para o estudo do fumo em nossas origens e na história da colonização do Brasil, dando uma possibilidade de se pensar nos aspectos geográficos relacionados. No estudo dessa temática, além de estudar sobre o funcionamento do corpo humano, os professores envolvidos buscaram em suas áreas de conhecimento elementos que pudessem contribuir para a conscientização sobre os agravos à saúde causados pelo cigarro e pela poluição.

Esta é, conforme Pinho-Alves e Schmitz (2004) e Fourez (1995), uma vivência interdisciplinar de aproximação disciplinar que limita professor e alunos a uma análise pautada em um paradigma disciplinar; o projeto foi compartilhado entre os professores, mas não houve o compromisso compartilhado com um produto final de modo explícito.

\section{Tema gerador de discussão em foco}

Até o ano de 1999 os professores das séries iniciais do Cepae, interessados por estudos interdisciplinares, ainda atuando com mais de uma 
disciplina em uma mesma série (os professores se organizavam em blocos de disciplinas, Matemática e Ciências ou Matemática e Português, por exemplo), estiveram entre as duas propostas: tomando uma obra literária como centro dos temas e discutindo os valores humanos a ela pertinentes ou tomando um conteúdo como central e buscando nas outras áreas de conhecimento elementos que contribuíssem para a compreensão do conteúdo. O que ocorria, entretanto, era que os professores desenvolviam atividades tratando de um mesmo assunto, sendo que uma disciplina se tornava central, enquanto outras se tornavam secundárias, até o momento em que fosse escolhido um assunto que favorecesse a mudança do centro.

Grande inquietação surge, principalmente junto aos professores de Matemática, pois se tornava difícil cumprir o plano de curso sem os vários afastamentos momentâneos do trabalho coletivo. De fato, o trabalho a partir de um tema náo facilita o cumprimento do plano de curso de forma sistemática e os professores não conseguiam colocar um conteúdo de Matemática como foco. Estas inquietaçôes foram motivadoras da investigação "O ensino de matemática através de unidades temáticas", desenvolvida entre os anos de 1999-2000, financiada pela FUNAPE (Fundação de Apoio à Pesquisa) e coordenada por mim (Barreto et al., 2001). No contexto de tal investigação foi realizado um estudo do plano de curso de matemática desenvolvido na escola e nele identificado como características a linearidade e a hierarquização. A partir desse estudo, houve uma reestruturação deste plano em função do que nos era solicitado pela dinâmica do trabalho interdisciplinar, de modo que pudesse colaborar para a compreensão de um determinado dado da realidade do aluno.

A compreensão de um dado da realidade transcende o olhar de uma área de conhecimento específica. Esta transcendência fez com que se explicitasse a dificuldade dos professores para se soltarem das amarras de um plano de curso e se integrarem a uma proposta de trabalho interdisciplinar. Isto se torna ainda mais evidente quando, ao desenvolver a investigação proposta, indicamos partir de um tema a ser problematizado conforme a realidade do grupo de alunos, de modo que a unidade temática fosse o ponto de encontro das diversas disciplinas e que cada uma pudesse contribuir para a compreensão/reflexão sobre o tema em estudo. Assim, não seria um tema/conteúdo simplesmente, mas um tema problematizável amplo e que trouxesse como característica ser epocal, universal, local, tal como defende Paulo Freire (1987). 
No contexto de uma temática em estudo, a Matemática, assim como qualquer área de conhecimento, não pode ser estudada de maneira linear, sendo necessário promover situaçóes em que o aluno atue sobre os objetos de estudo, buscando (re)significá-los a partir da busca de relaçôes com o que conhece, formulando hipóteses e elaborando conjecturas. A primeira unidade temática proposta para estudo, que comporia o solo da investigaçáo, centrou as reflexóes em um tema amplo - "Direitos e Deveres da Criança e do Adolescente" - inserido no contexto dos direitos humanos. Foram pesquisadas atividades que favorecessem discussóes sobre o assunto, refletindo acerca do papel do serviço público no suprimento das necessidades básicas da comunidade e do papel de cada um na transformação dessa realidade. Alguns obstáculos e esclarecimentos se explicitaram no desenvolvimento da investigação e serão explicados a seguir.

\section{Obstáculos para o trabalho com temas geradores de discussão}

Inspirado pela pedagogia de Paulo Freire (1987), o tema foi tomado por Barreto et al. (2001) como tema gerador de discussão em sala de aula e teve como característica suscitar discussóes de situaçóes/problemas possíveis de serem enfrentados por crianças da nossa comunidade escolar e poder ser conhecido a partir de formas diferentes de registro da cultura (obras literárias, jornais, obras de arte em geral, depoimentos e pesquisas de opiniāo entre alunos e seus familiares). No contexto de um tema gerador de discussão, o grupo se preocupava também com a formação de conceitos e a socialização dos conhecimentos historicamente construídos pelas diversas ciências.

Conforme Barreto et al. (2001), na análise do estudo desenvolvido, o trabalho a partir de tema gerador de discussão pode contribuir para uma organização menos hierarquizada e fragmentada do conhecimento trabalhado na escola, além de uma contextualização do conteúdo proposto no programa de ensino, mas não favorece o cumprimento de um plano de curso linear de qualquer que seja a disciplina. Isso gera desconforto, tal como expresso por uma professora das séries iniciais em reunião de avaliação do trabalho da $1^{\text {a }}$ Fase do Ensino Fundamental, no final do primeiro semestre do ano de 2000: 
[1]

Parar o conteúdo para interdisciplinar foi lúdico, foi agradável, mas... e o específico da disciplina? [...] Quero algo mais frutífero, como tenho colhido. Interdisciplinaridade é bonitinho. (Professora do $3^{\circ}$ ano)

A reflexão a que tal depoimento nos remete (Barreto et al., 2001) é que para se pensar um trabalho interdisciplinar é necessário que os professores vejam a disciplina com a qual trabalham como uma área de conhecimento que pode contribuir para o estudo do mundo vivido, mais que como uma estrutura que favorece o cumprimento de conteúdos. Isto não significa que, ao abordar o tema família, por exemplo, todos os professores devessem utilizar textos que falassem de seus integrantes, tratando daquilo que lhe é mais comum, aparente. As discussóes poderiam girar em torno do conjunto de relaçóes possíveis de serem pensadas a partir da existência dessa instituição: como se produzem cultura, bens e serviços e relaçóes no contexto da origem, formação e manutenção da família brasileira, mudanças ambientais e sociais provocadas pelas novas formas de relaçóes em seu seio, e vice-versa.

Outra grande dificuldade apresentada (Barreto et al., 2001) diz respeito ao momento do planejamento de uma unidade temática, conforme depoimento da professora:

[2]

Estamos aprendendo a fazer planejamento: ou não levamos material, porque náo pesquisamos, ou pesquisamos e levamos tudo fechado... Acho que não estamos sabendo trabalhar. Há boa vontade, mas não estamos sabendo trabalhar. No planejamento último houve uma conversa que orientou para uma unidade mais crítica. (Professora do $1^{\circ}$ ano)

A professora ressalta aspectos que apontam caminhos para a diminuição das dificuldades encontradas: deve-se pesquisar sobre o assunto antes de ir para o planejamento coletivo; não se deve levar modelos de atividades para serem desenvolvidas, mas sugestóes para serem discutidas; é preciso que os professores discutam e reflitam sobre o modo como as várias áreas de conhecimento podem contribuir para o estudo do tema $\mathrm{e}$ compartilhem elementos específicos de sua área de conhecimento.

No encaminhamento do trabalho proposto foi possível presenciar situaçóes de resistência e dificuldades, mas também atitudes de estudo, de criatividade, pesquisa, envolvimento e outras mais que possibilitaram 
compartilhar compreensões e concepções entre os professores-parceiros de um planejamento coletivo.

\section{Aulas de Matemática e o tema gerador de discussão: a disciplinaridade em questáo}

Não há, em nossos estudos, pesquisadores que eliminem por completo a estrutura disciplinar da escola. O que se espera é que o professor se torne autônomo, investigativo, criativo, isto é, que não se limite a seguir uma proposta curricular ditada por um livro didático, sem considerar os problemas vividos, os anseios do grupo de alunos com o qual convive. Espera-se ainda que o plano de curso seja projeto, que estabeleça objetivos a serem alcançados, que deixe abertura para que novos elementos sejam incorporados.

Para Machado (1995, p. 193)

Com o trabalho interdisciplinar, pretende-se o estabelecimento de uma intercomunicação efetiva entre as disciplinas, através da fixação de um objeto comum diante do qual os objetos particulares de cada uma delas constituem sub-objetos. É um instrumentalizar para a compreensão mais efetiva do real, buscando favorecer uma compreensão crítica do tema em questão.

Assim posto, parece ser um desafio, numa proposta interdisciplinar, fugir da hierarquização de conhecimentos. Como o conhecimento será construído junto com os alunos a partir de atividades autênticas, ou seja, aquelas que por dizerem respeito à vida dos alunos são mais significativas, não há como limitar o conteúdo da série nem distribuí-lo por bimestre. Há que se buscar o "uso de uma linguagem integral em contextos situacionais significativos” (Machado, 1995, p. 193), em currículos amplos, abertos, sem barreiras para a entrada de novos elementos/conteúdos/assunto/temas/perguntas.

$\mathrm{Na}$ dinâmica de trabalho em questão os conteúdos disciplinares não precisam ser tratados num tempo determinado, podem ser estudados durante todo o curso, conforme possibilidade de contextualização em projetos de trabalho. Assim, um mesmo conteúdo pode ser visto várias vezes em situaçóes diferentes sem a pretensão de esgotá-lo, mas de discuti-lo. Mesmo que no programa apareça uma organização isolada das outras disciplinas, ocorre uma tentativa de se promover a relaçáo entre a ciência e os proble- 
mas da sociedade que podem ser mais bem compreendidos com o auxílio de estudos específicos desenvolvidos pelas diversas áreas de conhecimento tratadas pela escola. Desta forma, não são menosprezadas as disciplinas, mas há a intenção de tratá-las como o que realmente são: instrumentos para o conhecimento do real. Não um real fragmentado, mas a realidade como um complexo. Assim, cada conteúdo do programa é trabalhado no contexto de problemas, cuja compreensão e estudo de possibilidades de solução se dão com a contribuiçẫo das várias disciplinas/áreas de conhecimentos, indo além da fragmentação aparente.

$\mathrm{Na}$ busca pela não-fragmentação no desenvolvimento da investigação, aqui descrita como um momento do processo de reflexão sobre interdisciplinaridade realizado historicamente no Cepae, foi realizada uma revisão do plano de curso, de modo que o mesmo favorecesse o desenvolvimento do sentido numérico, tal como nos propóe os estudos de Lins e Gimenez (1997), de Duhalde (1997) e de Lerner e Sadovsky (1996).

Lins e Gimenez (1997) propóem que a escola trabalhe com o desenvolvimento do sentido numérico. Partindo dos estudos da pesquisadora americana Judith Swouder, os autores (idem, p. 60) definem sentido numérico como "um conjunto de características e de uma rede de relaçóes que permitem relacionar números com operaçôes, com o objetivo de resolver problemas flexivelmente e mediante formas criativas". Para eles, o sentido numérico desenvolve-se mediante uma diversidade de experiências com os números em diferentes contextos, escolares ou não. $\mathrm{O}$ desenvolvimento do sentido numérico envolve estratégias como: capacidade de visualização; uso de números em contextos diferentes; uso de técnicas de composição e decomposição; compreensão do significado das operaçôes, bem como da diversidade de representações numéricas; comunicação de estratégias e controle e reflexão sobre a eficiência e aplicabilidade. É o desenvolvimento do sentido numérico que orienta o indivíduo na escolha da ferramenta mais adequada para a solução de problemas: cálculo mental, calculadora ou algoritmo.

Duhalde (1997, p. 74), pesquisadora argentina, apresenta como atividades centrais para o desenvolvimento do conceito de número as atividades de contagem e medição, pois tais atividades estão relacionadas às necessidades humanas de atuar e compreender o mundo em que se vive: "[...] o número surge pela necessidade de quantificar as quantidades contínuas e descontínuas que se encontram no espaço que nos rodeia, proporcionandonos uma melhor compreensão da realidade, tanto física quanto social”. 
Tais colocaçóes modificaram o modo como o trabalho de Matemática no ensino fundamental se desenvolvia. $\mathrm{O}$ estudo das medidas, do sistema monetário, por exemplo, tratado, muitas vezes, como aplicação do conhecimento numérico adquirido pelos alunos no decorrer do ano, deixa de existir como conteúdo e passa a ser trabalhado como contexto necessário ao entendimento dos números naturais, números decimais e fraçôes.

Lerner e Sadovsky (1996) ressaltam o papel de atividades que favoreçam a leitura e a produção da escrita numérica, orientando para que não haja uma limitação do contato das crianças com intervalos numéricos pré-definidos, pois elas interagem no mundo em que vivem, ao mesmo tempo, com cem, milhares e milhóes, elaborando critérios de comparação de seus valores de modo que, mesmo não conseguindo operar com números grandes, são capazes de identificá-los. Para que o aluno descubra as propriedades e a estrutura numérica, as autoras consideram duas categorias de atividades como básicas: comparar quantidades, produzir e interpretar números. As atividades de comparação e produçáo de interpretação de números contribuem para a elaboração de regularidades, o que ajuda os alunos a avançarem na compreensão do sistema numérico, aproxima a criança da notação convencional e auxilia no processo de contagem.

Partindo dessas consideraçóes o plano de curso foi organizado em três grandes grupos:

- Número Natural - produção e comparação de notações numéricas e operaçóes diversas no contexto da contagem, estatística; formação de grupos com relaçáo parte-todo (fração de quantidade e porcentagem);

- Número racional - produção e comparação de notaçóes numéricas e operaçóes diversas no contexto da mediçáo (comprimento, massa, capacidade, valor monetário), fração de quantidade e figuras, números decimais, porcentagem;

- Geometria- formas e medidas, sua presença no mundo.

Os três grupos de conhecimento deveriam ser trabalhados durante todo o ano, contextualizados em uma temática proposta. Para a compreensão do mundo vivido a matemática contribuiria fazendo perguntas que resultassem em descriçóes, quantificaçóes, mediçóes, comparações, valoraçóes e nomeaçóes, utilizando elementos da linguagem matemática. Como 
conseqüência, os alunos teriam a oportunidade de aprender, de modo contextualizado, os conteúdos propostos para as séries iniciais, todos eles contemplados nos grupos acima apresentados.

Como o incômodo que motivou a investigação esteve relacionado à possibilidade de se cumprir conteúdos ao trabalhar numa abordagem interdisciplinar, Barreto et al. (2001) realizaram um levantamento dos conteúdos trabalhados no desenvolvimento de aulas tendo como foco o estudo do tema "Escola - um direito da criança e do adolescente, dever do estado e da família”. Para esse levantamento, foi desenvolvido um conjunto de atividades com uma turma da $3^{a}$ série do Ensino Fundamental ( $4^{\circ}$ ano) e, ao final de cada aula, os professores relatavam em seu diário de campo as discussóes realizadas e o conteúdo trabalhado observando o grau de complexidade atingido. O quadro abaixo expressa o modo como o tema foi tratado nas aulas de Matemática e que conteúdos foram utilizados para a sua compreensão.

Tabela 1 - Atividades, discussóes e conteúdos de Matemática

\begin{tabular}{|l|l|l|}
\hline \multicolumn{1}{|c|}{ ATIVIDADE } & \multicolumn{1}{|c|}{$\begin{array}{c}\text { DISCUSSÓES } \\
\text { PERTINENTES }\end{array}$} & \multicolumn{1}{c|}{$\begin{array}{c}\text { CONTEÚDO } \\
\text { TRABALHADO }\end{array}$} \\
\hline $\begin{array}{l}\text { 1- Quantificar os alunos do } \\
\text { Cepae considerando sexo e } \\
\text { série. }\end{array}$ & $\begin{array}{l}\text { A quantidade de } \\
\text { alunos atendidos pelo } \\
\text { Cepae. }\end{array}$ & $\begin{array}{l}\text { Número natural; } \\
\text { catalogação de dados de } \\
\text { pesquisa; construção de } \\
\text { gráficos; elaboração de } \\
\text { problemas; produçáo de } \\
\text { texto síntese da pesquisa. }\end{array}$ \\
\hline $\begin{array}{l}\text { 2- Leitura de quadro } \\
\text { demonstrativo da procura } \\
\text { de vagas no Cepae no ano } \\
\text { de 1999 e pesquisa para } \\
\text { informar-se sobre os dados } \\
\text { de 2000. }\end{array}$ & $\begin{array}{l}\text { Vagas nas escolas; } \\
\text { escola de qualidade. }\end{array}$ & $\begin{array}{l}\text { Número natural; adição } \\
\text { e subtração de números } \\
\text { naturais. }\end{array}$ \\
\hline $\begin{array}{l}\text { 3- Situaçóes problemas } \\
\text { envolvendo o acervo e o } \\
\text { funcionamento da biblioteca } \\
\text { do Cepae. }\end{array}$ & $\begin{array}{l}\text { A necessidade } \\
\text { de se cuidar da } \\
\text { conservação do } \\
\text { acervo da biblioteca. }\end{array}$ & $\begin{array}{l}\text { neqüência numérica com } \\
\text { números entre 1000 e } \\
\text { naturais. }\end{array}$ \\
\hline $\begin{array}{l}\text { 4- Problemas envolvendo } \\
\text { entradas em cinemas, } \\
\text { shows... }\end{array}$ & $\begin{array}{l}\text { O papel da carteira } \\
\text { de estudante. }\end{array}$ & $\begin{array}{l}\text { Idéia de \% relacionada à } \\
\text { fração 1/2; adição de valores } \\
\text { monetários. }\end{array}$ \\
\hline
\end{tabular}


(continuação)

\begin{tabular}{|c|c|c|}
\hline $\begin{array}{l}\text { 5- Preenchimento de nota } \\
\text { fiscal relativa à compra de } \\
\text { material escolar, conforme } \\
\text { lista solicitada pelo Cepae. }\end{array}$ & $\begin{array}{l}\text { O papel da nota } \\
\text { fiscal; o custo da } \\
\text { educação para as } \\
\text { famílias. }\end{array}$ & $\begin{array}{l}\text { Adição de números } \\
\text { decimais no contexto } \\
\text { do sistema monetário; } \\
\text { multiplicação por dez } \\
\text { no contexto do sistema } \\
\text { monetário; porcentagem } \\
\text { relacionada à fração 1/2. }\end{array}$ \\
\hline $\begin{array}{l}\text { 6- Preenchimento de tabela } \\
\text { envolvendo o peso dos } \\
\text { alunos e o peso de suas } \\
\text { mochilas. }\end{array}$ & $\begin{array}{l}\text { Problemas de saúde } \\
\text { causados por excesso } \\
\text { de peso. }\end{array}$ & $\begin{array}{l}\text { Subtração de valores } \\
\text { decimais no contexto da } \\
\text { medida de massa; fração } \\
(1 / 10 \text { e } 1 / 5) \text { no referido } \\
\text { contexto. }\end{array}$ \\
\hline $\begin{array}{l}\text { 7- Estudo comparativo do } \\
\text { preço do uniforme entre dois } \\
\text { anos consecutivos. } \\
\text { - Situaçóes problemas } \\
\text { envolvendo compra de } \\
\text { uniforme. }\end{array}$ & $\begin{array}{l}\text { O custo do uniforme } \\
\text { no Cepae e o custo } \\
\text { da educaçáo para as } \\
\text { famílias. }\end{array}$ & $\begin{array}{l}\text { Subtração/adição de } \\
\text { números decimais no } \\
\text { contexto do sistema } \\
\text { monetário; porcentagem } \\
\text { relacionada à fração de } 1 / 2 \text {; } \\
\text { idéia de desconto. }\end{array}$ \\
\hline $\begin{array}{l}\text { 8- Pesquisa entre os alunos } \\
\text { do Cepae para saber em } \\
\text { que disciplinas têm mais } \\
\text { dificuldades. }\end{array}$ & $\begin{array}{l}\text { As dificuldades } \\
\text { existentes no trato } \\
\text { com algumas áreas de } \\
\text { conhecimento. }\end{array}$ & $\begin{array}{l}\text { Número natural; } \\
\text { catalogação de dados } \\
\text { de pesquisa; construção } \\
\text { de gráficos, idéia de } \\
\text { porcentagem. }\end{array}$ \\
\hline $\begin{array}{l}\text { 9- Situaçóes problemas } \\
\text { envolvendo distância e } \\
\text { tempo utilizado no percurso } \\
\text { da casa à escola. }\end{array}$ & $\begin{array}{l}\text { As dificuldades de } \\
\text { acesso à escola em } \\
\text { algumas regióes do } \\
\text { país. }\end{array}$ & $\begin{array}{l}\text { Número decimais no } \\
\text { contexto de medida de } \\
\text { espaço; idéia de quilômetro } \\
\text { e fraçáo de quilômetro; } \\
\text { idéia de horas e fraçáo de } \\
\text { horas. }\end{array}$ \\
\hline $\begin{array}{l}\text { 10- Estudo da linha de } \\
\text { tempo construída a partir da } \\
\text { história do Cepae. }\end{array}$ & $\begin{array}{l}\text { As modificaçóes } \\
\text { ocorridas no Cepae } \\
\text { através dos tempos }\end{array}$ & $\begin{array}{l}\text { Subtração envolvendo } \\
\text { tempo passado. }\end{array}$ \\
\hline $\begin{array}{l}11 \text { - Leitura do fragmento da } \\
\text { reportagem sobre o trabalho } \\
\text { infantil. }\end{array}$ & $\begin{array}{l}\text { O trabalho infantil } \\
\text { como empecilho para } \\
\text { a presença da criança } \\
\text { na escola. }\end{array}$ & $\begin{array}{l}\text { Números decimais; } \\
\text { números naturais. }\end{array}$ \\
\hline
\end{tabular}

Fonte: relatório de pesquisa Barreto et al. (2001).

Um estudo da seqüência de atividades permite ver como possibilidade a inserção, nas aulas de matemática, de situaçôes vivenciais do 
dia a dia, textos informativos (jornalísticos ou científicos) e literários a ela relacionados. Todos esses elementos, além de serem motivadores para o estudo, podem servir como contexto para diversos conteúdos previstos no plano de curso. Ao analisar o número presente tanto nas situações do dia a dia como nos textos, pode-se, além de compreendê-lo, discutir as informaçôes a ele relacionadas, com possibilidade de formação de opinião e construção de argumento, tâo importantes para o desenvolvimento do espírito crítico.

Pode-se observar que alguns conteúdos foram tratados mais de uma vez, outros presentes no plano de curso de $3^{a}$ série ainda não foram explorados no estudo desta temática, mas poderiam ser abordados nas unidades temáticas que se seguiriam. Isto se contrapóe à idéia de hierarquia e linearidade no tratamento do conhecimento matemático.

O tratamento do tema deu-se a partir do paradigma das disciplinas abordando várias áreas de conhecimento e favoreceu a discussão de assuntos referentes ao acesso e à permanência do aluno na escola, uma caracterizaçáo da escola de qualidade para que possam reivindicar os seus direitos, a saúde do escolar, história e modificação dos uniformes e da rotina da escola através dos tempos, e, ainda, o cumprimento de alguns conteúdos do programa da série.

Esse modo de encaminhar o trabalho pedagógico apresenta uma característica multidisciplinar, conforme Pinho-Alves e Schmitz (2004), visto que cada professor seleciona os conteúdos programáticos possíveis de relacionar ao tema. Os alunos podem participar na escolha do tema, entretanto, como não há um projeto e um produto final que comprove a participação e a necessidade de participação das disciplinas, há uma ausência de negociação compromissada por parte dos envolvidos.

\section{Organização do trabalho pedagógico e o desenvolvimento de projetos interdisciplinares}

As mudanças ocorridas na organização do trabalho pedagógico das séries iniciais do ensino fundamental a nosso ver muito contribuíram para as mudanças ocorridas nas propostas de trabalho com vistas a uma ação interdisciplinar.

Em 1990, os professores eram responsáveis por grande parte das disciplinas trabalhadas (excetuando artes e educação física). Havia um mo- 
mento para planejamento coletivo por série de modo que os professores de séries iguais e turmas distintas podiam compartilhar atividades e modos de encaminhar as aulas. O tempo desse professor na sala de aula com o grupo de alunos era de 20 horas/aula semanais. Entre 1994 a 2001 os professores se organizaram assumindo blocos de disciplinas (matemática, ciências; português, história e geografia, sendo esta organização flexível) e realizavam planejamentos coletivos, buscando uma intercomunicação entre as propostas de trabalho. Nesse modo de organização o professor ficava com o mesmo grupo de alunos por um período de aproximadamente 10 horas/ aula semanais. A partir de 2001, os professores das séries iniciais, que antes trabalhavam com mais de uma disciplina em sala de aula, compartilhando atividades e desenvolvendo planejamentos compartilhados com outros professores de outras turmas, passaram a tratar uma única disciplina em várias séries, nos mesmos moldes como é desenvolvido o trabalho com a segunda fase do Ensino Fundamental ( $6^{\circ}$ ao $9^{\circ}$ ano).

$\mathrm{O}$ argumento principal para esta mudança foi a necessidade de redução de carga horária em sala de aula, de modo que os professores pudessem cumprir o que lhes era exigido pela carreira de magistério superior: ensino, pesquisa e extensão, orientação de estágio, atuação em cursos de pós-graduação, entre outras atividades específicas do ambiente escolar. A mudança se sustentou também na possibilidade de os professores poderem aprofundar estudos relativos ao conhecimento das disciplinas articulados a um aprofundamento de questóes relativas à educação, pois em cada grupo disciplinar haveria licenciados em áreas específicas e pedagogos. Entretanto, tal articulação não se efetivou de fato: os professores-pedagogos passaram a ocupar salas comuns a professores-licenciados em disciplinas específicas, que focam em seu fazer pedagógico aspectos disciplinar-conteudistas; se distanciaram dos companheiros de série, o que inviabilizou uma intercomunicação que possibilitasse elaborar um projeto compartilhado.

Na nova estrutura, os momentos de planejamento, que antes serviam para discutir atividades elaboradas, compartilhá-las e compartilhar modos de encaminhá-las em sala de aula, foram substituídos por encontros cada vez mais esparsos, para falar dos problemas disciplinares das turmas e para que os professores comunicassem o que esperavam fazer nas aulas focando os conteúdos que pretendiam abordar. Esta prática nas atividades de planejamento não propicia a intercomunicação entre 
as disciplinas, uma vez que o foco não está centrado em um problema, um tema, uma situação vivida, mas em conteúdos de uma estrutura curricular disciplinar.

A realidade acima descrita mostrou-se preocupante em diferentes momentos do trabalho pedagógico, como, por exemplo, quando Santos e Brito (2007), ao realizarem seu estágio para conclusão do curso de Licenciatura em Matemática, se propuseram a desenvolver, numa turma de $5^{\circ}$ ano, um estudo em torno da temática "Nem luxo, nem lixo", entendendo que tal temática possibilitaria discutir sobre o lixo e suas conseqüências em nosso ambiente. Elas náo conseguiram parceiros para a realização do trabalho, pois cada professor estava envolvido com o propósito estabelecido para sua própria disciplina. Mesmo sem parcerias as alunas realizaram o trabalho, puderam estudar medidas de volume e capacidade, tempo, valores monetários, números decimais, fraçóes, proporção. Tiveram um ambiente propício para o estudo das operaçôes de adição, subtração, multiplicação, divisão. Todos esses conteúdos contribuindo para um mapeamento da realidade vivida em nosso planeta, favorecendo a elaboração de estratégias para modificar a situação vivida.

Como conclusão do trabalho realizado, Santos e Brito (2007) avaliam como necessária a atuação das demais áreas de conhecimento para o enriquecimento do trabalho proposto, pois este teria sido mais produtivo se os textos trabalhados nas aulas de Matemática tivessem sido estudados, com mais profundidade, pelos professores de Ciências, Geografia e Português, problematizados sob o foco da área de conhecimento específica.

Enfim, com as mudanças ocorridas nos últimos anos o trabalho solitário toma o espaço do trabalho solidário que estava sendo construído e o individualismo torna-se característico, dificultando a construção de uma proposta de trabalho interdisciplinar. Se no percurso seguido foram explorados caminhos que favoreciam ao trabalho interdisciplinar, agora, diante da nova estrutura, ainda não se conseguiu uma articulação que viabilize a retomada desta possibilidade.

Ao tentarmos olhar, com isenção da paixão, para os caminhos percorridos e para o trabalho realizado fica a consciência de que parecia que estávamos tão pertos de fazer uma escola mais viva, perto de colocarmos o conhecimento a serviço de nossa compreensão de mundo e da possibilidade de transformá-lo. 


\section{Revista Solta a Voz, v. 19, n. 2}

\section{O QUE CONCLUIR...}

As reflexões realizadas ao longo deste trabalho foram também conclusivas. Entendemos que o trabalho interdisciplinar solicita um trabalho coletivo; solicita um planejamento em que os envolvidos compartilhem compreensóes, ansiedades e dividam o trabalho de modo que cada um possa trazer a sua contribuição para a compreensão do mundo vivido, de modo que a ciência seja tratada em sua complexidade e não de modo simplificado e sem relação com o vivido, sempre dinâmico e complexo; solicita um grupo de professores interessados em rever sua ação pedagógica, rever seu plano de curso, rever sua concepção do conhecimento e de escola. Somente um professor-pesquisador, um professor-reflexivo, se permitirá seguir o caminho do impreciso, do inacabado e imprevisível, falível, irregular característico.

Para Fazenda (1994, p. 92), "O projeto interdisciplinar parte da dúvida, da pergunta, das indagaçóes, do diálogo da troca, da reciprocidade”. Os caminhos percorridos por nós, professores do Cepae, apontaram para a necessidade de ir além da tematização rumo a uma problematização. E as indicaçôes de Fourez (1995) nos apontam a necessidade de não somente partir de um tema e do conhecimento das várias disciplinas para a sua compreensão, mas pensar em um projeto compartilhado que permita a negociação compromissada com o projeto e com um produto final.

Enfim, falar de interdisciplinaridade na escola tem sido falar do desejo de uma organização da prática pedagógica de modo mais articulado, menos fragmentado. É falar do desejo de ver a ciência trabalhada na escola saindo do espaço escolar e contribuindo para que o aluno utilize o conhecimento veiculado pela escola para tomar decisóes, realizar escolhas, agir no seu dia a dia de modo consciente, modificando e ao mesmo tempo respeitando o ambiente no qual vive e o grupo com quem compartilha esse ambiente. Sem o desejo que impulsionará o professor para a pesquisa, para a criatividade, para o diálogo e a busca da compreensão de si mesmo, do que faz, na tentativa de fazer sempre melhor, parece não ser possível se pensar num trabalho interdisciplinar.

\section{REFERÊNCIAS}

BARRETO, M. F. T. et al. Tema gerador de discussão: contextualizando a Matemática em sala de aula. Relatório de Pesquisa. Goiânia: Cepae/UFG, 2001. 
CACHAPUZ, A. et al. Da educação em Ciência às orientaçóes para o ensino das Ciências: um repensar epistemológico. Ciência e educação, v. 10, n. 3, p. 363-381, 2004.

DUHALDE, M. E. Ao encontro da matemática. In: CUBERES, M. T. G. (Org.). Educação infantil e séries iniciais: articulação para a alfabetização. Trad. de Cláudia Schilling. Porto Alegre: Artes Médicas, 1997. p. 73-94.

FAZENDA, I. C. A. Interdisciplinaridade: história, teoria e pesquisa. Campinas: Papirus, 1994. (Coleção Magistério: Formação e Trabalho Pedagógico)

FOUREZ, G. A construção das ciências: introdução à filosofia e à ética das ciências. São Paulo: UNESP, 1995.

FREIRE, P. Pedagogia do oprimido. 28. ed. Rio de Janeiro: Paz e Terra, 1987.

GUIMARÃES, L. D; PINTO, M. P. Análise quantitativa do termo Interdisciplinaridade no período de 1970 a 2004. Multiciência: tecnologia para a saúde, v. 5, p. 1-14, 2005.

LERNER, D: SADOVSKY, P. O sistema de numeração: um problema didático. In: PARRA, C.; SAIZ, I. (Orgs.). Didática da matemática: reflexóes psicopedagógicas. Trad. de J. A. Llorens. Porto Alegre: Artes Médica, 1996. p.73-154.

LINS, R. C.; GIMENEZ, J. Perspectivas em aritmética e álgebra para o século XXI. Campinas: Papirus, 1997.

MACEDO, E; CAMPOS, A. A estabilidade do currículo disciplinar: o caso das ciências. In: . Disciplinas e integração curricular: história e políticas. São Paulo: DP e A editora, 2000.

MACHADO, N. J. Epistemologia e didática: as concepçôes de conhecimento e inteligência e a prática docente. São Paulo: Cortez, 1995.

PIETROCOLA, M. et al. Prática interdisciplinar na formação disciplinar de professores de ciências. Disponível em: http://www.if.ufrgs.br/public/ ensino/vol8/n2/v8_n2_a3.html. Acesso em: 06 mai. 2008.

PINHO-ALVES, J.; SCHMITZ, C. Componentes de uma ilha de interdisciplinaridade de racionalidade. In: $V$ Encontro sobre Investigação na Escola, 2004, Lajeado. Atas do V EIE, 2004. 


\section{Revista Solta a Voz, v. 19, n. 2}

SANTOS. D. B; BRITO. M. C. R. S. Interdisciplinaridade por meio de unidade temática. Trabalho de Final de Curso (Licenciatura em Matemática) - Instituto de Matemática e Estatística-UFG, 2007.

TEIXEIRA, M. F. A construção do conceito em Ciências. Revista Solta a Voz, Goiânia, v. 1, p.43-46, 1994.

Recebido em: 14 maio 2008 Aceito em: 25 ago. 2008 